\title{
Disposition of WR-1065 in the Liver of Tumor-bearing Rats Following Regional vs Systemic Administration of Amifostine
}

\author{
Micha Levi ${ }^{a, b, *}$, Susan J. DeRemer ${ }^{b}$, Chunzhi Dou ${ }^{b}$, William D. Ensminger ${ }^{b, c}$ and David E. Smith ${ }^{a, b}$ \\ ${ }^{a}$ College of Pharmacy, The University of Michigan, Ann Arbor, Michigan, USA \\ ${ }^{\mathrm{b}}$ Upjohn Center for Clinical Pharmacology, The University of Michigan, Ann Arbor, Michigan, USA \\ ${ }^{\mathrm{c}}$ Department of Pharmacology and Internal Medicine, The University of Michigan, Ann Arbor, Michigan, USA
}

\begin{abstract}
Purpose-Amifostine is a prodrug in which selectivity is largely determined by the preferential formation and uptake of its cytoprotective metabolite, WR-1065, in normal tissues as a result of differences in membrane-bound alkaline phosphatase activity. It was hypothesized that amifostine may be a good candidate for regional drug delivery to the liver because of its large hepatic extraction and total body clearance. Methods-Rat livers were implanted with Walker-256 tumors. The tumor-bearing rats received $15 \mathrm{~min}$ infusions of amifostine $(200 \mathrm{mg} / \mathrm{kg})$ via the portal vein or the femoral vein. WR-1065 concentrations in the blood, liver and tumor were measured at various times. Results - The WR-1065 tumor portal dosing $A U C_{15-60}$ was $40 \%$ of systemic dosing, and tumor concentrations following portal dosing were one-fifth of that following systemic dosing. The portal dosing WR-1065 liver $A U C_{15-60}$ was $60 \%$ higher than the values for systemic dosing. The liver/tumor concentration ratios of WR-1065 following portal dosing were up to 8-fold higher than the ratio following systemic administration. Unfortunately, systemic exposure to WR-1065 was greater following portal vs systemic amifostine. Conclusions-Amifostine may provide increased liver protection and decreased tumor protection from radio- or chemotherapy when administered by the portal vein. However, portal dosing also increases systemic exposure to WR-1065, which is associated with hypotension. Copyright (C) 2004 John Wiley \& Sons, Ltd.
\end{abstract}

Key words: amifostine; tissue pharmacokinetics; WR-1065; regional drug delivery

\section{Introduction}

The tolerance of the liver to radiation therapy or chemotherapy is too low to permit effective treatment of hepatic carcinoma [1]. Therefore, investigating strategies that could potentially increase the therapeutic index of chemotherapy or radiotherapy in the liver is of major importance. Amifostine is a potent chemo- and radioprotective agent that has been shown to protect various tissues from the cytotoxic effects of radiation and/or chemotherapy without com-

*Correspondence to: Dr M. Levi, Box 0626, University of California, San Francisco, CA 94143-0626, USA.

E-mail: micha@c255.ucsf.edu promising tumor cell kill [2-5]. Amifostine is a phosphorylated prodrug that is selectively hydrolysed in healthy tissue to the active metabolite, the free thiol, WR-1065 [6]. In turn, WR-1065 detoxifies the active species associated with radiotherapy and chemotherapy by forming covalent bonds with alkylating agents, scavenging free radicals and other mechanisms $[7,8]$. Alkaline phosphatase is the enzyme that is responsible for the hydrolysis of amifostine to WR-1065 [9]. This enzyme is membrane-bound and localized in the blood vessels of tissues/ organs. Amifostine exerts its selectivity towards benign tissue due to the differences in alkaline phosphatase distribution and $\mathrm{pH}$ between normal and tumor tissue. Tumors are less 
vascularized than benign tissue and, therefore, less alkaline phosphatase is available to activate amifostine to WR-1065 in the tumor. Furthermore, tumor $\mathrm{pH}$ is lower than that of normal tissue and alkaline phosphatase is less efficient in hydrolysing amifostine in the low $\mathrm{pH}$ environment of tumor cells. Finally, low $\mathrm{pH}$ may decrease the rate of amifostine uptake into cells [8].

The dose-limiting adverse effect of amifostine is transient hypotension, which is dose dependent and is associated with direct relaxation of vascular smooth muscle mediated by WR-1065 [10]. Amifostine has a very high clearance and short half-life, and there is some evidence suggesting that its pharmacokinetics is saturable [11]. The main metabolic pathway of WR-1065 elimination involves the formation of symmetrical and nonsymmetrical disulfides that might serve as a depot for the subsequent release of active metabolite [12].

Regional pharmacokinetic experiments in dogs have demonstrated that the liver has a high rate of amifostine activation (i.e. $E_{\mathrm{H}} \approx 0.9$ ), a process that was not saturated over a wide dose range [13]. Since the selective protection of healthy tissue by amifostine is dependent on the localized conversion of the parent drug to WR-1065, this high conversion rate suggested that the liver might also be protected by amifostine.

Regional drug delivery is an approach designed to increase the therapeutic index of chemotherapy. Compared with systemic delivery, higher drug concentrations can be achieved at the desired target site and/or lower concentrations can be delivered to sites of systemic toxicity. Collins [14] derived an equation that predicts the potential advantage of regional drug delivery. The potential advantage of amifostine regional administration to the liver $(R \mathrm{~d})$, calculated using the Collins equation, is between 20 and 37 , indicating that regional administration of amifostine to the liver will produce a liver/ systemic concentration ratio that is 20-37 fold higher than the ratio achieved following systemic administration. Liver $R d$ values were estimated using amifostine clearance and liver extraction ratios values from regional pharmacokinetic studies in the dog [13]. However, this estimation is limited because amifostine is a prodrug and
WR-1065 concentrations would actually determine liver protection. Nevertheless, our hypothesis is that regional administration of amifostine to the liver would enhance WR-1065 selectivity to that region, since amifostine is converted solely to WR-1065, and local conversion and uptake could occur in normal tissue. Regional drug delivery has been proven to be a valuable method to increase the therapeutic index of other chemotherapeutic drugs [15-17]. Therefore, regional administration could potentially increase the amifostine therapeutic index and, in turn, allow escalating doses of radiation and/or chemotherapy to be delivered to the liver without inducing toxicity or compromising tumor cell kill.

Amifostine is administered in the clinic as a $15 \mathrm{~min}$ infusion $30 \mathrm{~min}$ before the start of chemotherapy or radiotherapy [18]. However, the recommended regimen may be too limited. For example, activation in different tissues and/ or different administration routes may affect the optimal start time for chemotherapy or radiotherapy following amifostine administration. To date, little experimental data supporting the clinically approved administration regimen are available.

In the present study, our objective was to evaluate the potential advantage of amifostine regional administration to the liver. Thus, the concentrations of the active metabolite, WR-1065, were determined in the blood, liver and tumor of a tumor-bearing rat model. Rats received a $200 \mathrm{mg} / \mathrm{kg}$ dose of amifostine over an infusion period of $15 \mathrm{~min}$, a regimen which is similar to that used clinically. To evaluate regional administration to the liver, rats received amifostine either through the femoral vein (systemic dosing) or through the portal vein (regional dosing).

In an attempt to further increase selectivity of protection of the liver compared with the tumor, systemic and portal venous infusions were compared. This reflects the fact that the tumors in the liver are vascularized primarily through the hepatic artery, whereas the normal liver receives most of its blood supply from the portal system [19,20]. Thus, amifostine selectivity in the liver might be further enhanced by use of the portal vein for regional administration. 


\section{Methods}

\section{Animals}

Male Sprague-Dawley rats weighing approximately 250-300 g were obtained from Harlan Sprague Dawley, Inc. (Indianapolis, Indiana). They were housed in cages in a temperaturehumidity controlled room with a $12 \mathrm{~h}$ light-dark cycle and fed with 5001 Rodent Diet (PMI Nutrition International, Inc. Brentwood, Mo). All animal procedures and study protocols were approved by the University of Michigan Committee on the Use and Care of Animals.

\section{Tumor implantation}

The animals were anesthetized using a $60 \mathrm{mg} / \mathrm{kg}$ intraperitoneal injection of pentobarbital. A midline abdominal incision was made and the liver was exposed. Walker 256 cells were grown in suspension cultures with RPMI media supplemented with $10 \%$ fetal calf serum and prepared for injection by suspension in Hanks media. The left lateral lobe and the right median lobe were both injected with tumor cells $(0.1 \mathrm{ml})$ and the peritoneum and abdominal wall were closed. Focal tumors were allowed to grow for 12-14 days. The average size of the tumors at the time of amifostine administration was $1.2 \pm 0.3 \mathrm{~cm}$ by $1 \pm 0.4 \mathrm{~cm}$ (measured using a ruler). The average weight of the tumors at the time of dosing was $440 \pm 299 \mathrm{mg}$.

\section{Amifostine administration}

The animals were anesthetized using a $60 \mathrm{mg} / \mathrm{kg}$ intraperitoneal injection of pentobarbital and the femoral vein or portal vein was cannulated, as previously described [21]. A $1 \mathrm{ml}$ aliquot of warm saline was injected over $60 \mathrm{~s}$ into the portal vein and the surgical bed was examined for leakage. A dilution of $200 \mathrm{mg} / \mathrm{kg}$ amifostine (ALZA Pharmaceuticals, Palo Alto, or CA/US Bioscience, West Conchohocken, PA) in normal saline was prepared $5 \mathrm{~min}$ prior to the start of the infusion. The amifostine solution was administered over $15 \mathrm{~min}$ using a syringe pump (Harvard Apparatus, South Natick, MA) set at $83.5 \mu \mathrm{l} / \mathrm{min}$.

\section{Experimental protocol}

Tumor-bearing rats were divided randomly into two equal groups, each receiving amifostine either through the portal vein (regional) or the femoral vein (systemic). Tumor and liver tissue were collected 15, 20, 30, 45 and $60 \mathrm{~min}$ after initiating the drug infusion. In order to reduce animal-to-animal variability during blood sampling, parallel experiments were conducted in a different group of tumor-bearing rats in which serial samples were obtained. In these studies, six blood samples $(0.4 \mathrm{ml})$ were sequentially drawn from the femoral vein before amifostine dosing (time zero) and at 15, 20, 30, 45 and 60 min after initiating the drug infusion. Blood samples were replaced with equal volumes of warm normal saline. In the blood sampling experiments, four animals were studied after each dosing route (i.e. systemic and regional).

\section{Assay for WR-1065}

WR-1065 is a free thiol that can readily form disulfide bonds with proteins. In this study the concentrations of free WR-1065 were measured in the blood and in various tissues as described below.

Sample preparation. The method was adopted from Shaw and coworkers $[6,11]$ with minor modifications. Tumor and liver samples were dissected, rapidly rinsed with ice-cold normal saline, weighed and frozen rapidly by dipping them in a liquid nitrogen bath for $30 \mathrm{~s}$. The samples were stored at $-70^{\circ} \mathrm{C}$ for subsequent analysis. On the day of analysis, the samples were homogenized $(1: 2.5, \mathrm{w} / \mathrm{v})$ in an ice-cold buffer containing $1.0 \mathrm{M}$ perchloric acid and $2.7 \mathrm{~mm}$ EDTA, as described previously [6,11]. The homogenate was then centrifuged at $1000 \mathrm{~g}$ for $10 \mathrm{~min}\left(\right.$ at $0^{\circ} \mathrm{C}$ ) and WR251833 was added as an internal standard. The samples were kept on ice during the entire procedure in order to minimize the hydrolysis of amifostine to WR-1065.

Blood samples were placed in tubes, containing ice-cold $1.0 \mathrm{M}$ perchloric acid and $2.7 \mathrm{~mm}$ EDTA in a ratio of $1: 1(\mathrm{v} / \mathrm{v})$, immediately after sampling. The mixture was then vortexed vigorously and centrifuged at $1000 \mathrm{~g}$ for $10 \mathrm{~min}$ (at $0^{\circ} \mathrm{C}$ ). The supernatant was stored at $-70^{\circ} \mathrm{C}$ for

Biopharm. Drug Dispos. 25: 27-35 (2004) 
subsequent analysis. On the day of analysis, the samples were thawed, WR-251833 was added as an internal standard, and a $20 \mu \mathrm{l}$ aliquot was injected into the HPLC. Likewise, all samples were kept on ice during the entire procedure in order to minimize the hydrolysis of amifostine to WR-1065. Using the described method, the lower limit of detection for WR-1065 was $1.0 \mu \mathrm{M}$. The method was validated by measuring samples that were spiked with known concentrations of WR-1065 (1, 4, 10 and $50 \mu \mathrm{M})$ on four different days. The interday variability (precision) of WR1065 was less than $8.4 \%$ and the accuracy (bias) was less than $8.6 \%$.

HPLC analysis. Analysis was performed on a Kratos (Ramsey, New Jersey) Spectraflow 400 HPLC pump. WR-1065 and the internal standard were detected using a BAS (West Lafayette, Indiana) LC-4C amperometric detector equipped with a thin film mercury-gold amalgam electrode. The $\mathrm{Hg} / \mathrm{Au}$ electrode working potential was set at $+0.15 \mathrm{~V}$ with respect to the $\mathrm{Ag} / \mathrm{AgCl}$ reference electrode. The column, $100 \times 3 \mathrm{~mm}$, $3 \mu \mathrm{m}$ particle size, ODS BAS (West Lafayette, Indiana), was operated at room temperature. The WR-1065 chromatography protocol employed a mobile phase containing $0.1 \mathrm{M}$ of monochloroacetic acid, 3 mm sodium-octyl sulfate $\mathrm{pH} 3.0$, and $30 \%$ methanol running at $0.6 \mathrm{ml} / \mathrm{min}$. Peak identification was confirmed by comparing retention times in samples with authentic standards. Quantification was based on the peak area ratio of the compound and the internal standard.

\section{Statistics}

Data are reported as mean \pm SD unless otherwise indicated. A two-tailed Student's $t$-test was used to compare drug samples. A $p$ value of $\leqslant 0.05$ was statistically significant. Area under the curve was determined noncompartmentally using WinNonlin version 3.1 (Pharsight, Mountain View, California).

\section{Results}

WR-1065 concentrations in the tumor, liver and blood, after regional or systemic dosing of amifostine, are shown in Figure 1. As observed in Figure 1A, WR-1065 concentrations in the tumors were lower after portal vein infusion compared with the femoral vein infusion at the 15, 20 and $30 \mathrm{~min}$ time points. These data suggest that portal vein administration of amifostine offers less tumor protection than femoral vein administration. At the $20 \mathrm{~min}$ time point, the mean tumor concentrations of WR-1065 were 44.8 and $229 \mu \mathrm{M}$ for regional and systemic dosing, respectively. At the 15 and 30 min time points, the mean tumor concentrations of WR-1065 were 84.8
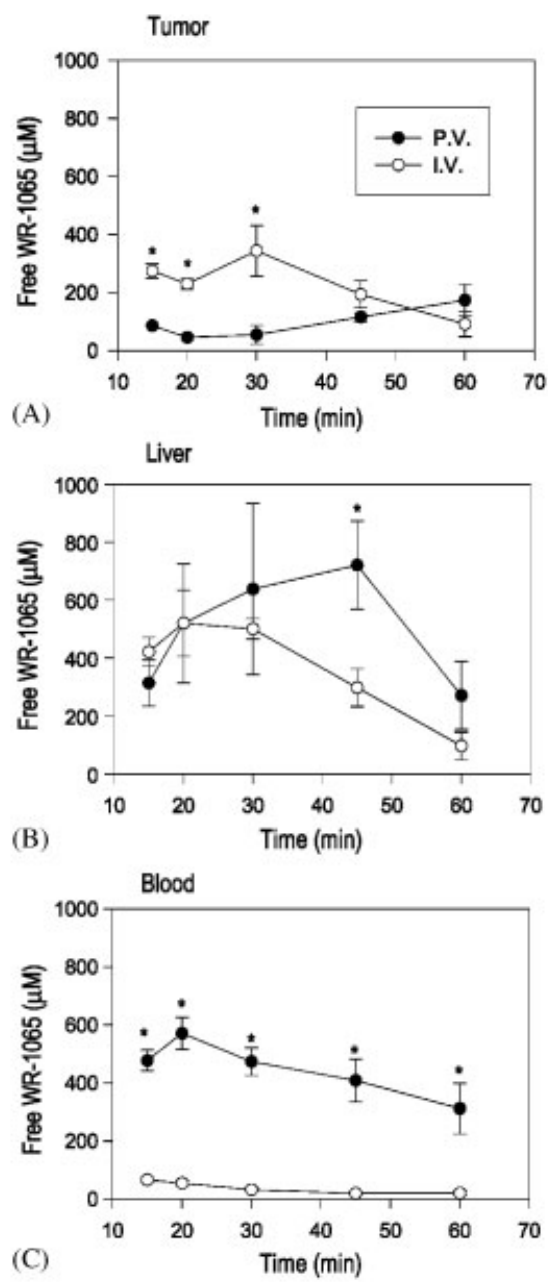

Figure 1. WR-1065 concentrations in the tumor (A), liver (B), and blood (C) of tumor-bearing rats following a $15 \mathrm{~min}$ infusion of amifostine via the portal vein (p.v.) or femoral vein (i.v.). Data represent the mean \pm SE from 3-4 determinations. *Significant difference $(p \leqslant 0.05)$ 
and $53.7 \mu \mathrm{M}$, respectively, after portal vein dosing while the mean tumor concentrations were much higher (273 and $343 \mu \mathrm{M}$, respectively), following femoral vein dosing. Thus, a favorable trend exists for lower WR-1065 tumor concentrations following portal vein compared with femoral vein administration of amifostine.

The concentrations of WR-1065 in the liver are shown in Figure 1B. As seen in this figure, WR1065 concentrations appeared higher in the liver after portal vein dosing at the 30, 45 and $60 \mathrm{~min}$ time points. However, a statistically significant difference occurred only at the 45 min time point. The data suggest that portal vein infusion of amifostine offers only marginally better liver protection compared with femoral vein administration. In addition, it should be noted that the liver $t_{\max }$ of WR-1065 occurred at $20 \mathrm{~min}$ after systemic dosing while the liver $t_{\max }$ of active metabolite occurred at $45 \mathrm{~min}$ after regional dosing. The mean WR-1065 $C_{\max }$ was $720 \pm$ $263 \mu \mathrm{M}$ in liver after regional dosing while the mean WR-1065 $C_{\max }$ was $519 \pm 355 \mu \mathrm{M}$ in liver after systemic dosing of amifostine.

The blood concentrations of WR-1065 are shown in Figure 1C. As displayed in this figure, WR-1065 blood concentrations were higher following a portal vein infusion compared with a femoral vein infusion of amifostine. The data indicate that portal vein administration of amifostine results in a significant increase in WR1065 systemic exposure and that of femoral vein administration. The mean WR-1065 $C_{\max }$ in blood was $572 \pm 108 \mu \mathrm{M}$ after regional dosing, while it was only $65.9 \pm 18.6 \mu \mathrm{M}$ after systemic dosing. The blood $t_{\max }$ after regional infusion was observed at $20 \mathrm{~min}$; in contrast, the blood $t_{\max }$ after systemic infusion was observed immediately after cessation of amifostine infusion (at $15 \mathrm{~min})$. In addition, it should be noted that the coefficient of variation (\%CV) after femoral vein administration was considerably lower than after portal vein infusion $(27.2 \%$ and $42.2 \%$, respectively).

Figure 2 shows the liver/tumor concentration ratios of WR-1065 following femoral vein or portal vein infusions of amifostine to tumorbearing rats. As observed, the liver/tumor concentration ratios after portal vein administration were always greater than the ratios after femoral

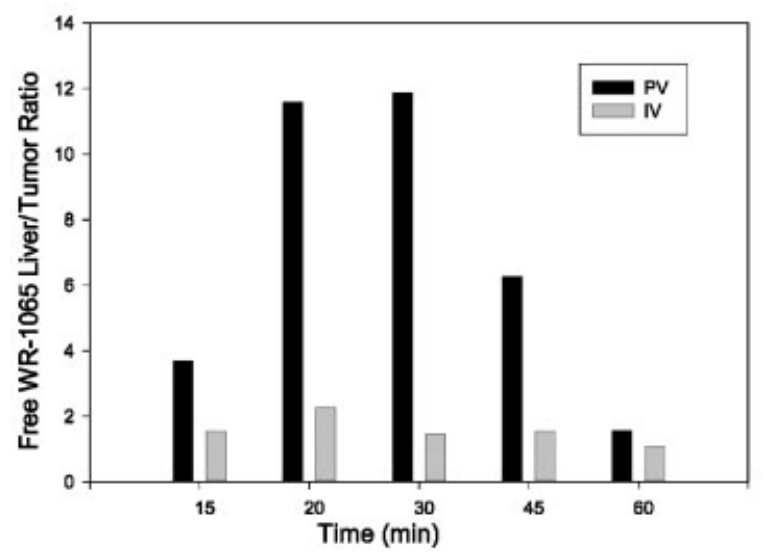

Figure 2. Liver/tumor concentration ratios of WR-1065 in tumor-bearing rats after a $15 \mathrm{~min}$ infusion of amifostine via the portal vein (p.v.) or femoral vein (i.v.). Bars represent the ratio of mean data

vein infusion. The largest difference was achieved at the $30 \mathrm{~min}$ time point, when the liver/tumor concentration ratio of WR-1065 reached a maximum of about 12 after regional dosing while the ratio after systemic dosing was only about 1.5 . The data suggest that portal vein administration of amifostine would offer increased liver protection and reduced tumor protection compared with femoral vein administration of drug.

Figure 3 shows the route-dependent concentration ratio of WR-1065 (p.v./i.v.) in the tumor, liver and blood. As seen in this figure, WR-1065 blood concentrations were as much as 21 times higher after portal vein than after femoral vein administration. Likewise, the liver concentrations of WR-1065 were as much as three times higher after portal vein administration compared with femoral vein administration. In contrast, tumor levels of WR-1065 after portal administration were one-fifth of the levels after femoral vein administration. The data suggest that while amifostine offers a beneficial reduction in tumor protection, portal vein administration of amifostine offers a marginal increase in liver protection as well as a substantial increase in systemic exposure to WR-1065.

The body weight, dose, blood $C_{\max }, A U C_{15-60}$ and dose-normalized $A U C_{15-60}$ of WR-1065 after 
portal vein or femoral vein administration to tumor-bearing rats are shown in Table 1. As shown in this table, there were no significant differences between rat weight and dose amount. The $C_{\max }$ of WR-1065 following systemic admin-

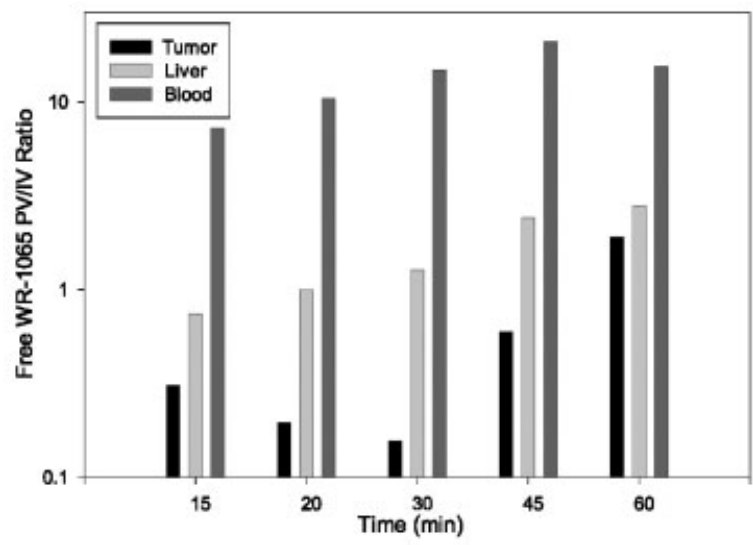

Figure 3. Concentration ratios of WR-1065 (p.v./i.v.) in the blood, liver and tumor of tumor-bearing rats after a $15 \mathrm{~min}$ infusion of amifostine via the portal vein (p.v.) or femoral vein (i.v.). Bars represent the ratio of mean data istration was $66 \mu \mathrm{M}$, a value that is about nine times smaller than the $C_{\max }$ following portal vein administration $(572 \mu \mathrm{M})(p=0.0001)$. The $A U C_{15-60}$ of WR-1065 after portal vein infusion was $19339 \pm 1580 \mathrm{~min} \mu \mathrm{mol} / \mathrm{l}$, a value more than 13 times that of WR-1065 after femoral vein administration $\quad(1420 \pm 497 \mathrm{~min} \mu \mathrm{mol} / \mathrm{l}) \quad(p<0.0001)$. Furthermore, the dose-normalized $A U C_{15-60}$ of WR-1065 was $287 \pm 32$ and $21.2 \pm 8.7 \mathrm{~min} / 1$ after portal vein and femoral vein administrations, respectively $(p<0.0001)$. These findings indicate that portal vein infusions of amifostine result in nonlinear behavior of WR-1065 in the blood.

The body weight, dose, liver or tumor $C_{\max }$ $A U C_{15-60}$ and dose normalized $A U C_{15-60}$ of WR1065 after portal vein or femoral vein dosing to tumor-bearing rats are shown in Table 2. As seen in this table, the $A U C_{15-60}$ value of WR-1065 in the liver was about $60 \%$ higher after regional dosing compared with systemic drug administration. In contrast, the $A U C_{15-60}$ value of WR1065 in tumor after regional dosing was about $40 \%$ of the $A U C_{15-60}$ value after systemic drug administration. In addition, the dose normalized

Table 1. WR-1065 values in the blood of tumor-bearing rats for $C_{\max }, A U C_{15-60}$ and dose normalized $A U C_{15-60}$ after a 15 min infusion of amifostine via the portal vein (p.v.) or femoral vein (i.v.) ${ }^{\mathrm{a}}$

\begin{tabular}{llccr}
\hline Parameter & Unit & p.v. & i.v. & $p^{\mathrm{b}}$ \\
\hline Body weight & $\mathrm{g}$ & $337 \pm 12$ & $342 \pm 26$ & 0.7408 \\
Dose & $\mu \mathrm{mol}$ & $315 \pm 11$ & $320 \pm 25$ & 0.7408 \\
$C_{\max }$ & $\mu \mathrm{mol} / 1$ & $572 \pm 109$ & $65.9 \pm 18.6$ & 0.0001 \\
AUC $_{15-60}$ & $\mathrm{~min} \mu \mathrm{mol} / 1$ & $19339 \pm 1580$ & $1420 \pm 497$ & $<0.0001$ \\
AUC $_{15-60} /$ dose & $\mathrm{min} / \mathrm{l}$ & $288 \pm 32$ & $21.2 \pm 8.7$ & $<0.0001$ \\
\hline
\end{tabular}

${ }^{\text {a }}$ Data are mean $\pm \mathrm{SD}(n=4)$.

${ }^{\mathrm{b}} p$ values were determined by two-tailed $t$-test.

Table 2. WR-1065 values in the liver and tumor of tumor-bearing rats for $C_{\max }, A U C_{15-60}$ and dose normalized $A U C_{15-60}$ after a 15 min infusion of amifostine via the portal vein (p.v.) or femoral vein (i.v.) ${ }^{\text {a }}$

\begin{tabular}{|c|c|c|c|c|c|}
\hline \multirow[t]{2}{*}{ Parameter } & \multirow[t]{2}{*}{ Unit } & \multicolumn{2}{|l|}{ Liver } & \multicolumn{2}{|c|}{ Tumor } \\
\hline & & p.v. & i.v. & p.v. & i.v. \\
\hline Body weight $^{a}$ & $\mathrm{~g}$ & 385 & 369 & 385 & 369 \\
\hline Dose $^{a}$ & $\mu \mathrm{mol}$ & 360 & 345 & 360 & 345 \\
\hline$C_{\max }^{\mathrm{b}}$ & $\mu \mathrm{mol} / 1$ & 720 & 520 & 173 & 343 \\
\hline$A U C_{15-60}{ }^{c}$ & $\min \mu \mathrm{mol} / 1$ & 25474 & 16402 & 4239 & 10263 \\
\hline$A U C_{15-60} / \operatorname{dose}^{c}$ & $\min / 1$ & 70.8 & 47.6 & 11.8 & 29.8 \\
\hline
\end{tabular}

${ }^{\text {a }}$ Mean of 18 rats for p.v. or i.v. treatment.

${ }^{\mathrm{b}}$ Mean of 3 rats, representing one time point.

${ }^{c}$ AUC calculated using 5 time points, with 3 rats per time point. 
$A U C_{15-60}$ values in liver were 70.8 and $47.6 \mathrm{~min} / 1$ after portal vein and femoral vein infusions, respectively. In the tumor, however, the dosenormalized $A U C_{15-60}$ values were $11.8 \mathrm{~min} / 1$ after portal vein infusion and $29.8 \mathrm{~min} / 1$ after femoral vein infusion. These findings further illustrate that WR-1065 tumor exposure was reduced but that WR-1065 liver exposure was increased following regional as opposed to systemic infusion of drug.

\section{Discussion}

In the present study, our main finding was that portal vein administration of amifostine increased WR-1065 selectivity to the liver compared with systemic administration. This is indicated by the reduction of WR-1065 tumor concentrations following regional dosing to as much as one-fifth the concentrations achieved following intravenous infusion. The maximum decrease occurred at the 20 and $30 \mathrm{~min}$ time points. This finding was further supported by $A U C_{15-60}$ values of WR-1065 in tumor after regional dosing that were about $40 \%$ of the tumor $A U C_{15-60}$ values after intravenous infusion. Moreover, WR-1065 concentrations in the liver increased after p.v. amifostine infusion compared with intravenous infusion of the same dose. WR-1065 concentrations in the liver after p.v. amifostine were more than twice the concentrations after i.v. dosing at the 45 and $60 \mathrm{~min}$ time points. Similarly, the $A U C_{15-60}$ values of WR-1065 in the liver after p.v. amifostine were about $60 \%$ higher than the $A U C_{15-60}$ values after i.v. administration. Finally, the liver/tumor concentration ratios of WR-1065 after p.v. amifostine were larger than these ratios after i.v. infusion of amifostine for all the time periods tested. In particularly, at the $30 \mathrm{~min}$ time point, the liver/ tumor ratio of WR-1065 after portal vein amifostine reached a maximum value of about 12 , whereas the ratio after intravenous infusion was only about 1.5 . These findings demonstrate that, in comparison with intravenous amifostine, portal vein infusion of the drug increased liver exposure and reduced tumor exposure to WR1065. Hence, liver protection from radio- and/or chemotherapy might well increase, while tumor protection might decrease.

These findings agree with our previous predictions that portal vein infusion of amifostine may be advantageous over systemic delivery because of its ability to increase liver selectivity. Our predictions were based on the high total body clearance of amifostine and high liver extraction in dogs [13]. Additionally, differences in the blood supply between healthy liver and tumor tissue $[19,20]$ may contribute toward the selective targeting of benign tissue after p.v. drug administration.

Unfortunately, p.v. infusions of amifostine increased substantially the systemic exposure to WR-1065, compared with i.v. infusion of the same dose. In turn, this higher exposure to WR-1065 could result in hypotension that might limit the clinical use of p.v. infusions of parent drug [10]. Our study indicated that the $A U C_{15-60}$ of WR1065 in blood following p.v. administration of amifostine was 14 times higher than the $A U C_{15-60}$ values after i.v. administration. This apparent nonlinear behavior of WR-1065, following regional amifostine infusion, could be the result of saturation in one or more of the metabolic pathways involved in the elimination of WR-1065. Alternatively, a WR-1065 induced reduction in blood flow may be responsible for this nonlinear behavior. The concentration of a drug presented to the liver after p.v. infusion was at least four times greater than the concentration presented to the liver after systemic administration of the same dose [22]. Thus, the higher concentrations of amifostine (and presumably WR-1065) presented to the liver might result in the nonlinear pharmacokinetic behavior observed in WR-1065 blood concentrations. A similar nonlinearity in the pharmacokinetics of WR-1065 following p.v. infusion of amifostine was observed in monkeys [22]. In this study, rhesus monkeys received a $10 \mathrm{~min}$ infusion of $150 \mathrm{mg} / \mathrm{kg}$ amifostine by p.v. or i.v. dosing. The plasma AUC of WR-1065 following p.v. infusion was about $60 \%$ greater than following i.v. infusion. The considerably higher increase in WR-1065 AUC seen in our study, compared with the Mangold study (14-fold vs 1.6-fold, respectively), could be attributed to differences in species (rats versus monkeys), differences 
in dose $(200 \mathrm{mg} / \mathrm{kg}$ versus $150 \mathrm{mg} / \mathrm{kg})$ and in disease state (tumor-bearing rat versus healthy monkeys). The reason for choosing the $200 \mathrm{mg} /$ $\mathrm{kg}$ dose in our study was that this dose is the minimum amount shown to have a radioprotective effect in rats [23], with an irradiation dose modification factor of approximately 2 in hepatocytes. This dose was also used in other rat experiments [24,25].

We conclude that because p.v. administration of amifostine significantly reduced tumor concentrations of the active metabolite, WR-1065, tumor protection from radio- and/or chemotherapy may also be significantly reduced. Moreover, the modest increase in the liver exposure to WR-1065 resulting from p.v. amifostine infusion may provide some increased protection of healthy liver tissue. One significant drawback, however, is that p.v. infusions of amifostine did substantially increase systemic concentrations of WR-1065 and might, thereby, increase the likelihood of hypotension. The mechanism of an increased systemic WR-1065 after p.v. infusion of amifostine is unclear at present. However, it may be due to saturability of WR-1065 disposition or, alternatively, a reduction in blood flow to the eliminating organs. Additional dose ranging experiments are warranted to evaluate the nature of the apparent nonlinear pharmacokinetics of amifostine and WR-1065, particularly after regional dosing. This is especially important if additional clinical benefit is to be achieved by using amifostine as a chemo- and radioprotectant agent during the treatment of hepatic cancer.

\section{Acknowledgements}

This work was supported in part by grant number CA098502 from the National Institutes of Health.

\section{References}

1. Lawrence TS, Robertson JM, Anscher MS, Jirtle RL, Ensminger WD, Fajardo LF. Hepatic toxicity resulting from cancer treatment. Int J Radiat Oncol Biol Phys 1995; 31: 1237-1248.

2. Milas L, Hunter N, Reid BO, Thames HD. Protective effects of S-2-(3-aminopropylamino)-ethyl-phosphorothioic acid against damage of normal tissues and a fibrosarcoma in mice. Cancer Res 1982; 42: 1888-1897.

3. Milas L, McBride WH, Hunter N, Ito H. Protection by S-2-(3-aminopropylamino) ethylphosphorothioic acid against radiation- and cyclophosphamide-induced attenuation in antitumor resistance. Cancer Res 1984; 44: 2382-2386.

4. Rasey JS, Spence AM, Badger CC, Krohn KA, Vera DM, Livesy JC. Specific protection of different normal tissues. Pharmac Ther 1988; 39: 33-43.

5. Rasey JS, Nelson NJ, Mahler P, Anderson K, Krohn KA, Menard T. Radioprotection of normal tissues against gamma rays and cyclotron neutrons with WR-2721: $\mathrm{LD}_{50}$ studies and ${ }^{35} \mathrm{~S}-\mathrm{WR}-2721$ biodistribution. Radiat Res 1984; 97: 598-607.

6. Risley JM, Van Etten RL, Shaw LM, Bonner H. Hydrolysis of S-2-(3-aminopropylamino)ethylphosphorothioate (WR2721). Biochem Pharmacol 1986; 35: 1453-1458.

7. Snyder RD, Grdina DJ. Further evidence that the radioprotective aminothiol, WR-1065, catalytically inactivates mammalian topoisomerase II. Cancer Res 2000; 60: 1186-1188.

8. Capizzi RL. The preclinical basis for broad-spectrum selective cytoprotection of normal tissues from cytotoxic therapies by amifostine (ethyol). Eur J Cancer 1996; 32A Suppl 4: S5-S16.

9. Calabro-Jones PM, Fahey RC, Smoluk GD, Ward JF. Alkaline phosphatase promotes radioprotection and accumulation of WR-1065 in V79-171 cells incubated in medium containing WR-2721. Int J Radiat Biol 1985; 47: 23-27.

10. Ryan SV, Carrithers SL, Parkinson SJ et al. Hypotensive mechanisms of amifostine. J Clin Pharmacol 1996; 36: 365-373.

11. Shaw LM, Bonner HS, Brown DQ. Metabolic pathways of WR-2721 (ethyol, amifostine) in the BALB/c mouse. Drug Metab Dispos 1994; 22: 895-902.

12. Shaw LM, Bonner HS, Lieberman L. Pharmacokinetic profile of amifostine. Semin Oncol 1996; 23: 18-22.

13. Levi M, Knol JA, Ensminger WD et al. Regional pharmacokinetics of amifostine in anesthetized dogs: role of the liver, gastrointestinal tract, lungs and kidneys. Drug Metab Dispos 2002; 30: 1425-1430.

14. Collins JM. Pharmacologic rationale for regional drug delivery. J Clin Oncol 1984; 2: 498-504.

15. Ensminger WD, Rosowsky A, Raso V et al. A clinicalpharmacological evaluation of hepatic arterial infusions of 5-fluoro-2'-deoxyuridine and 5-fluorouracil. Cancer Res 1978; 38: 3784-3792.

16. Wagner JG, Gyves JW, Stetson PL et al. Steady-state nonlinear pharmacokinetics of 5-fluorouracil during hepatic arterial and intravenous infusions in cancer patients. Cancer Res 1986; 46: 1499-1506.

17. Blesing $\mathrm{CH}$, Kerr DJ. Intra-hepatic arterial drug delivery. J Drug Targeting 1996; 3: 341-347. 
18. PDR. In Physicians' Desk Reference 54 edn. Medical Economics Company: Montvale, NJ, 2000.

19. Ridge JA, Bading JR, Gelbard AS, Benua RS, Daly JM. Perfusion of colorectal hepatic metastases. Relative distribution of flow from the hepatic artery and portal vein. Cancer 1987; 59: 1547-1553.

20. Sigurdson ER, Ridge JA, Kemeny N, Daly JM. Tumor and liver drug uptake following hepatic artery and portal vein infusion. J Clin Oncol 1987; 5: 1836-1840.

21. Jansons RA, Mosier Jr HD. A simplified method for chronic portal vein cannulation in the rat. Physiol Behav 1986; 38: 739-741.

22. Coleman MD, Fleckenstein L, Geary RS, Brewer TG, Timony GA, Mangold DJ. The disposition of ethiofos
(WR-2721) in the isolated perfused rat liver. Radiat Res 1989; 117: 334-341.

23. Jirtle RL, Pierce LJ, Crocker IR, Strom SC. Radiation protection of rat parenchymal hepatocytes with S-2-(3aminopropylamino)ethylphosphorothioic acid. Radiother Oncol 1985; 4: 231-237.

24. Yuhas JM. Active versus passive absorption kinetics as the basis for selective protection of normal tissues by S-2-(3aminopropylamino)-ethylphsphorothioic acid. Cancer Res 1980; 40: 1519-1524.

25. Symon Z, Levi M, Ensminger WD, Smith DE, Lawrence TS. Selective radioprotection of hepatocytes by systemic and portal vein infusions of amifostine in a rat liver tumor model. Int J Radiat Oncol Biol Phys 2001; 50: 473-478. 